\title{
A formação de magistrados como instrumento de transformação da justiça
}

The Role of Judicial Training to the Justice Transformation

La formation de magistrats comme instrument de transformation de la justice

\section{Conceição Gomes}

\section{(2) OpenEdition}

\section{Journals}

Edição electrónica

URL: http://journals.openedition.org/rccs/7881

DOI: $10.4000 /$ rccs.7881

ISSN: 2182-7435

Editora

Centro de Estudos Sociais da Universidade de Coimbra

Edição impressa

Data de publição: 7 Novembro 2018

Paginação: 237-260

ISSN: 0254-1106

Refêrencia eletrónica

Conceição Gomes, "A formação de magistrados como instrumento de transformação da justiça », Revista Crítica de Ciências Sociais [Online], Número especial | 2018, colocado online no dia 05 novembro 2018, criado a 30 abril 2019. URL : http://journals.openedition.org/rccs/7881 ; DOI $10.4000 /$ rccs. 7881 


\title{
CONCEIÇÃO GOMES
}

\section{A formação de magistrados como instrumento de transformação da justiça*}

\begin{abstract}
A formação dos atores judiciais deve orientar-se pelo objetivo estratégico de criação de uma cultura jurídica fortemente comprometida, tanto com a qualidade, eficiência e transparência da justiça, como com o seu ativismo democrático, seja na promoção de direitos humanos e direitos fundamentais, seja no combate à criminalidade grave, em especial à corrupção. A questão central que se coloca é saber se os modelos de formação quer das faculdades de direito, quer da formação profissional, têm ou não potencial para responder a esse objetivo estratégico. A conclusão pela prevalência de uma formação de orientação tecnocrática, formalista e fechada à interdisciplinaridade e às inovações com potencial de criação dessa cultura judiciária exige que a política de formação seja colocada no centro das agendas estratégicas de reforma da justiça.
\end{abstract}

Palavras-chave: cultura jurídica; formação profissional; magistrados; reforma da justiça; tribunais.

\section{Introdução}

O protagonismo social e político dos tribunais tem vindo a aumentar em abrangência e em complexidade. E, se é certo que as respostas aos grandes desafios do nosso tempo (riscos de destruição massiva, profundas desigualdades e múltiplas invisibilidades sociais, policentrismo de poderes fáticos, entre outros) não passam pelos tribunais, todos os dias, em todo o mundo, os tribunais são chamados a tomar decisões, não só com forte impacto na vida quotidiana de cidadãos e de empresas, mas também nas condições políticas e sociais de funcionamento da comunidade. Sintoma desse protagonismo é a frequência com que expressões como "poder dos juízes", "tribunalcracia”, “juristocracia” e "governo dos juízes” surgem nas análises sobre os tribunais. São múltiplos os fatores indutores desse

\footnotetext{
* O presente artigo beneficia das análises desenvolvidas em vários estudos do Observatório Permanente da Justiça do Centro de Estudos Sociais da Universidade de Coimbra.
} 
protagonismo. Destaco, entre outros, as novas áreas de conflitualidade e de mobilização do direito, designadamente no campo da propriedade intelectual, do ambiente, da segurança alimentar, da medicina, da vida e da morte (barrigas de aluguer, reprodução medicamente assistida, eutanásia); a fragilização do poder político, em grande parte induzida por escândalos de corrupção e de cooptação de setores do Estado por interesses privados, levando à investigação e à condenação criminal de pessoas política e socialmente poderosas; o crescente escrutínio pelos tribunais da ação política, mobilizados por organizações da sociedade civil e/ou por cidadãos na luta contra a precarização e/ou retração de direitos; e o aumento exponencial das exigências securitárias e de controlo social, com o crescimento da criminalidade transnacional (cibercrime, tráfico de seres humanos, criminalidade económica, terrorismo, etc.), que convoca os tribunais, tanto para o combate a esses fenómenos criminais, como para a proteção de direitos e liberdades fundamentais cada vez mais comprimidos a coberto de políticas de combate e de prevenção de ações terroristas. Boaventura Sousa Santos sintetiza assim os fundamentos do protagonismo dos tribunais:

o crescente protagonismo dos tribunais é, antes de mais, o sintoma de uma dupla crise do Estado: como centro de regime democrático, a contas com uma crise de legitimidade, e como Estado-providência incapaz de manter altas expectativas dos cidadãos a seu respeito. (Santos, 2002: 151)

A criação de tribunais transnacionais, de que são exemplo no espaço europeu o Tribunal de Justiça da União Europeia e o Tribunal Europeu dos Direitos Humanos, cujas decisões têm forte impacto no desenvolvimento de políticas públicas de natureza financeira, ${ }^{1}$ comercial, ambiental, de proteção de direitos sociais e humanos, aprofundou aquele fenómeno.

Não é nova a convocação dos tribunais para o exercício de funções que ultrapassam o quadro comum de resolução de conflitos. Santos et al. (1996) identificam as seguintes funções dos tribunais: instrumentais, políticas e simbólicas. As funções instrumentais são as mais conhecidas e com maior profusão na literatura sociojurídica e consistem na resolução de litígios, no controlo social, na administração e criação de direito. As funções políticas dos tribunais decorrem, não só da sua condição de órgãos de soberania, mas também do controlo social que são chamados a exercer, em especial quando estão em causa crimes cometidos por pessoas com relevância política, da sua

\footnotetext{
${ }^{1}$ A posição do Tribunal de Justiça da União Europeia sobre o programa OMT - Outright Monetary Transaction permitiu iniciar a compra massiva pelo Banco Central Europeu de dívida soberana.
} 
mobilização para a afirmação de direitos fundamentais (expansão do judiciário para áreas típicas da ação governativa), cada vez mais precarizados, e do escrutínio sobre a ação política através da crescente transferência para o campo do judiciário da resolução de problemas de natureza política - fenómeno conhecido por judicialização da política, de que a crise na Catalunha é um excelente exemplo ${ }^{2}$-, colocando sob stress institucional o princípio da separação de poderes. A expansão da ação dos tribunais em domínios da governação política é hoje um campo de concretização das funções políticas com especial notoriedade. Entre nós, as decisões do Tribunal Constitucional contra medidas de austeridade com impacto na diminuição de rendimentos é a vertente mais mediática dessa expansão. As funções simbólicas dos tribunais são as funções mais amplas, incorporando tanto funções instrumentais, como políticas, constituindo a reserva de confiança dos cidadãos no funcionamento dos tribunais e na realização de justiça (Santos et al., 1996: 51-56). O que distingue o atual momento da ação dos tribunais é a amplitude e a complexidade das funções que são chamados a desempenhar, com destaque para as funções políticas, e as profundas transformações no contexto social da sua ação, marcado pela intensa globalização da vida em sociedade e da criminalidade (cibercrime, tráfico de seres humanos e de órgãos, criminalidade económica, terrorismo, entre outros), pela sociedade de informação, pela mediatização da justiça e por uma maior exigência social de eficiência, de qualidade, de proximidade e de transparência dos tribunais. Aos olhos dos cidadãos, os tribunais dessacralizaram-se de vez e, tal como outras organizações do Estado, o seu desempenho funcional é suscetível de escrutínio e de crítica pública.

Mas, se é verdade que o protagonismo e a expansão do judiciário vem ganhando importância e dimensão à escala global, os contornos e o seu significado sociopolítico são muito diferentes de país para país, dependendo de vários fatores, desde logo da posição do país no sistema-mundo e da cultura judiciária dominante. E nem sempre esse protagonismo e expansão fazem dos tribunais agentes de mudança democrática. Mandel (1995), ao analisar

\footnotetext{
${ }^{2}$ A Procuradoria-Geral espanhola, seguindo instruções do governo, acusou e pediu a prisão preventiva pela prática dos crimes de "sediação, rebelião e desvio de fundos" de vários membros dos partidos independentistas da Catalunha (Partido Democrata Europeu Catalão e Esquerda Republicana da Catalunha), que o tribunal decretou. Josep Ramoneda, num artigo publicado no jornal El País, de 24 de março de 2018, sintetiza bem a judicialização da política que se vive na Catalunha: "desde o primeiro momento, Rajoy optou por não assumir as suas responsabilidades políticas transferindo-as para o campo do judiciário e agora pagam-se as consequências. Um problema político transformou-se num problema judicial escapando ao controlo de Rajoy. Quem marca a agenda política não é o governo espanhol, mas sim o juiz Llarena” (Ramoneda, 2018; tradução da autora).
} 
a expansão judiciária no Canadá e na Itália, considerava-a, sobretudo no primeiro caso, antidemocrática. Tate e Vallinder (1995), partindo das análises dos autores do livro que coordenaram, ao abordarem os impactos dessa expansão na qualidade da democracia em vários países, mostram como os processos de expansão do poder judicial e da judicialização da política são simultaneamente relevantes e controversos. Na perspetiva do fortalecimento da democracia e da cidadania não é difícil defender a expansão do judiciário sempre que sobre ele recaem expectativas positivas na proteção dos direitos humanos e dos direitos fundamentais, mas nem sempre foi e é assim. São múltiplos os exemplos em que se vislumbram impactos antidemocráticos desta ação dos tribunais. Santos (2002 e 2013) alerta para isso mesmo.

O papel efetivo dos tribunais no aprofundamento democrático depende muito das condições em que é forjada a cultura judiciária. O sistema de formação dos atores judiciais, em especial dos magistrados, pode constituir um dos principais fatores indutores, quer da criação dessa cultura, quer da eficiência e qualidade da justiça. Neste artigo, procuro trazer para o debate algumas linhas de reflexão sobre a formação dos magistrados, considerando três dimensões: o ensino nas faculdades de direito, a formação inicial e a formação contínua. O objetivo é refletir sobre se os modelos de formação têm ou não potencial de criação de uma cultura judiciária fortemente comprometida, tanto com a qualidade, eficiência e transparência da justiça, como com o ativismo democrático dos tribunais, seja na promoção de direitos humanos e fundamentais, seja no combate à corrupção. O enquadramento dessa reflexão justifica que sublinhe, na secção seguinte, a relevância dos estudos sobre as profissões forenses, quer para a compreensão do funcionamento e do desempenho funcional dos tribunais, quer para a definição das políticas públicas da justiça.

\section{A relevância dos estudos sobre as profissões forenses}

$\mathrm{O}$ interesse académico pelos tribunais pode agregar-se em torno de três principais eixos analíticos: enquanto poder do Estado; enquanto sistema; e enquanto instituição profissional (Santos et al., 1996). A análise dos tribunais enquanto instituição profissional orienta-se para o desenvolvimento de estudos específicos sobre as transformações das profissões forenses. ${ }^{3}$ Numa categorização abrangente, é possível dividir esses estudos em dois grandes

\footnotetext{
${ }^{3}$ Com frequência, os conceitos de profissões jurídicas, profissões forenses e agentes da justiça são utilizados de forma indiferenciada. Utilizo o conceito de profissões jurídicas para referir os profissionais que, latu sensu, fazem uso, na sua atividade profissional, da racionalidade da ciência jurídica. O conceito de profissões forenses é mais restrito e é usado para referir os profissionais juristas aos quais a lei atribui competências específicas no âmbito dos processos judiciais.
} 
grupos: os que, partindo das profissões e do seu contexto, procuram avaliar o modo como influenciam a administração da justiça; e os que estudam as profissões, não partindo delas, mas de uma análise mais vasta sobre a organização e o funcionamento do sistema de justiça, procurando avaliar, em conjugação com outras dimensões, qual o papel dos profissionais na sua conformação e/ou transformação. No primeiro grupo é possível incluir os estudos que procuram conhecer, através da análise das origens, trajetórias, representações, valores dominantes e ideologias, quem são, o que pensam e como pensam os profissionais forenses, em especial os magistrados, e de que forma essas atitudes, trajetórias, identidades ou ideologias influenciam o exercício da sua atividade profissional, particularmente das suas decisões. São exemplos, na Europa, os estudos de José Juan Toharia $(1975,1989)$, Giuseppe Di Federico (1989) e Jean-Luc Bodiguel (1991). Em Portugal, destaca-se o primeiro estudo sociojurídico sistematizado sobre os magistrados judiciais e do Ministério Público "Quem são os nossos magistrados? Caracterização profissional dos juízes e magistrados do Ministério Público em Portugal", coordenado por António Casimiro Ferreira (2014). No segundo grupo situam-se os estudos que procuram analisar a dimensão profissional como variável do sucesso ou insucesso das reformas legais, da transformação do sistema judicial e do desempenho funcional dos tribunais (Santos et al., 1996; Garapon, 1998; Santos, 2002 e 2013; Nelken, 2004; Gomes et al., 2016; entre outros). Inserem-se neste grupo os estudos que analisam os critérios de ingresso, formação, progressão na carreira e avaliação dos profissionais, com destaque para o tema do recrutamento e da formação dos magistrados (Di Frederico, 2005; Santos et al., 2001 e 2006; Oberto, 2003; Épineuse, 2008; Santos e Gomes, 2011).

Apesar da sedimentação na tradição da sociologia do direito dos estudos sobre as profissões forenses, com especial incidência nas magistraturas e na advocacia, tal não invalida a constatação de António Casimiro Ferreira e outros no sentido da fraca base empírica em que assenta a maioria dos estudos:

a escassez dos estudos empíricos relativos às diversas profissões jurídicas e, em particular, às magistraturas, quer em termos comparativos, quer no âmbito de cada país, como fator primordial para a insuficiência de informação que permita contribuir para a elaboração de políticas públicas na área da justiça, bem como para avaliar qual a responsabilidade dos profissionais seja para a origem e perpetuação dos problemas ou o seu potencial/efetivo contributo para a superação das dificuldades. (Ferreira et al., 2013: 21) 
A centralidade da ação dos atores judiciais no desempenho funcional dos tribunais e na transformação democrática dos sistemas judiciais convoca o desenvolvimento de estudos empíricos sobre as profissões forenses capazes de produzir dados e análises robustas, fundamentais para a reflexão sobre as condições da sua transformação no quadro mais vasto de uma agenda estratégica para a reforma da justiça e dos tribunais. No seu livro Para uma revolução democrática da justiça, Boaventura de Sousa Santos considera que:

A atual crise económica e os atropelos diários às garantias jurídicas que dela decorrem, sobretudo a precarização dos direitos sociais, obrigam a perguntar: de que lado estão o direito e os tribunais? Do lado dos que querem destruir a democracia ou reduzi-la a uma formalidade sem substância ou do lado dos que querem defender a democracia e mesmo reforçá-la? (Santos, 2014: 13)

A resposta àquelas perguntas exige a compreensão das condições que os sistemas judiciais apresentam para se posicionarem de um ou de outro lado. Não é possível transformar o sistema judicial sem a criação de uma cultura jurídica que permita desenvolver e sustentar transformações democráticas da justiça. A criação dessa cultura depende muito da política de formação. O ensino do direito e a formação dos magistrados têm, na construção dessas condições e no desenvolvimento do pensamento alternativo de que fala Santos, um papel crucial. A questão central é a de saber se os atuais modelos de formação das faculdades de direito e do Centro de Estudos Judiciários (CEJ) reúnem condições para desempenhar esse papel e, em caso negativo, que transformações devem protagonizar para que a formação possa contribuir de forma relevante para a reivindicação e sustentação de reformas democráticas da justiça.

\section{O ensino do direito: a sociedade continua distante}

Embora a maioria dos estudos sociojurídicos se ocupe da formação profissional, o debate sobre a formação dos magistrados tem que incluir um debate mais amplo sobre o ensino do direito nas faculdades. A formação de base dos atores judiciais ocorre maioritariamente nas faculdades de direito e a interação entre o exercício profissional e o ensino universitário é, no campo do direito, muito próxima. Daí que as políticas com impacto na formação dos atores judiciais devam começar por refletir sobre a pergunta formulada por Christopher Gane e Robin Hui Huang (2016) "What are Law Schools for?" [Para que servem as faculdades de direito?], ainda que se compreenda que a abrangência e a complexidade a ela intrínsecas tornem muito difícil a resposta. Saliento, nesta secção, uma reflexão em torno do ensino nas 
faculdades de direito que procura avaliar se existem ou não dinâmicas de mudança com potencial de transformação da cultura jurídica e de capacitação dos futuros magistrados para melhor responderem aos desafios da complexidade social e jurídica. No quadro dos sistemas jurídicos continentais são escassas as análises críticas sobre o ensino do direito, sobretudo a partir das faculdades de direito, que permitam refletir sobre a adequação dos currículos e das metodologias de ensino às mudanças sociais, políticas e geracionais e estabelecer correlações entre os modelos de ensino e a conformação ou a transformação dos sistemas judiciais. Há, contudo, reflexões que levantam algumas pistas. Essas reflexões assentam no consenso de que a maioria das faculdades de direito europeias continua a privilegiar uma abordagem formalista e positivista do direito, que dificilmente transpõe as paredes das salas de aula e os textos legais, com os currículos e as metodologias de ensino tendencialmente imunes às múltiplas transformações sociais. ${ }^{4} \mathrm{O}$ processo de Bolonha e o movimento de europeização dos currículos (Reich, 2002) não trouxeram alterações significativas ao paradigma de ensino do direito, apesar de o sistema de créditos permitir uma maior flexibilização dos programas curriculares. Rodolfo Vázquez (2008), procurando responder a três questões (que direito se quer ensinar; qual a metodologia adequada a e coerente com esse conceito de direito; e que resultados ou objetivos se espera alcançar), identifica três modelos a partir de três conceções de ensino do direito: a) a conceção formalista ou positivista ortodoxa; b) a conceção crítico-realista, focando-se nos estudos críticos do direito (Critical Legal Studies); e c) a conceção democrática (defendida pelo autor) em que os princípios fundamentais do direito, como os princípios da autonomia pessoal, da dignidade humana e da igualdade - princípios base de uma sociedade democrática - devem assumir especial centralidade. O ensino jurídico deve, assim, dar especial atenção à formação dos atores judiciais para o ativismo judiciário em favor da defesa dos direitos humanos e fundamentais. A forte tradição positivista das universidades europeias leva ao predomínio do primeiro modelo, que privilegia a memorização e a separação de matérias por ramos de direito, assente em cinco principais axiomas: a) coercitividade do direito; b) imperatividade da norma jurídica; c) supremacia da lei sobre as restantes fontes do direito; d) plenitude e autossuficiência do sistema jurídico; e finalmente e) método da subsunção na aplicação silogística das normas (Pérez Lledó, 2002 e 2007). Neste modelo, o ensino do direito reconduz-se à explicação do ordenamento jurídico e à sua reprodução avalorativa e descritiva (Vázquez, 2008).

${ }^{4}$ Ver, entre outros, Ernest van Bemmemelen van Gent (2012) e Alberto Alemanno e Lamin Khadar (2018). 
Um tema recorrente no debate sobre o ensino do direito prende-se com a ponderação entre conteúdos programáticos mais teóricos ou mais orientados para a prática profissional. Este questionamento enquadra-se numa reflexão mais ampla sobre se as universidades devem recentrar-se ou não no desenvolvimento de uma formação direcionada para o mercado de trabalho, conferindo aos estudantes uma qualificação profissional. A progressiva massificação e industrialização da educação jurídica, tonando-a numa atividade que movimenta muitos milhões de dólares em todo o mundo (Santos, 2017; Alemanno e Khadar, 2018), a par da tendência de especialização em nichos de áreas do direito (Gent, 2012) dão lastro a esta perspetiva.

A interdisciplinaridade curricular, a especialização e a globalização do mercado das profissões jurídicas são outros temas do debate. Salientando a diferença em relação aos países anglo-saxónicos, em especial aos Estados Unidos da América (EUA), Bartosz Makowicz (2013) e Tomas Berkmanas (2013) chamam a atenção para a importância de os programas curriculares lhes darem relevância. Para o primeiro autor, os futuros juristas, além de terem que conhecer o direito aplicável, têm também que desenvolver competências que lhes permitam analisar e compreender plenamente os casos que estão no lastro dos processos judiciais, de modo a encontrarem a melhor solução jurídica. A defesa, identificável nos vários sistemas jurídicos de incorporação de outros saberes no próprio processo de decisão, permitindo aos tribunais respostas mais justas ao caso concreto, com destaque para os conflitos de família e relacionados com crianças, dá especial relevância a esta questão. Também a emergência, na Europa, do movimento de tribunais especializados em determinados tipos de crime, mas que procuram responder ao problema associado à conduta desviante (dependência de droga ou álcool, distúrbios mentais, precariedade económica) e ao seu impacto quer na vítima quer na sociedade - os designados "problem-solving courts" de longa tradição nos EUA -, ${ }^{5}$ bem como o debate sobre a excessiva criminalização da vida em sociedade e sobre medidas e penas alternativas à prisão colocam igualmente o enfoque na resposta judicial através de um processo colaborativo de outros saberes e de outras profissões. Tomas Berkmanas (2013), incidindo na profissão de advogado e na sua relação com o mercado de trabalho, salienta, além da dimensão da especialização, a universalização das profissões jurídicas. O impacto da globalização na educação jurídica é especialmente analisado por Christopher Gane e Robin Hui Huang (2016)

\footnotetext{
5 Sobre os princípios de "problem-solving justice" ver Wolf (2007). Para uma perspetiva crítica sobre o movimento dos "problem solving courts" a partir da experiência pioneira dos EUA, ver Quinn (2009).
} 
a partir de várias experiências, evidenciando-se a complexidade dos diferentes desafios e tensões que tal impacto representa para as universidades de implantação local, questionando Hans-Wolfgang Micklitz (2016) se os sistemas de ensino do direito da common law e continental têm o mesmo nível de abertura e a mesma capacidade de lidar com a transnacionalização da educação jurídica.

Numa outra perspetiva, de aproximação à sociedade, surgem temas como a relação entre ensino e investigação e a experiência de clínica jurídica. A clínica jurídica pode ser caraterizada em traços largos como método de ensino do direito baseado na aprendizagem através da experiência, mas que combina a prática jurídica dos estudantes, tutelada por professores, com a promoção do acesso ao direito de cidadãos com menos recursos económicos e a resolução pacífica dos conflitos. A experiência de clínica jurídica, com longa tradição nos EUA desde o início do século xx, foi amplamente difundida, desde os anos 60 e 70 do século passado, em vários países da common law, da América Latina e de África. À Europa continental a experiência chegou numa fase muito mais tardia. Só a partir de meados da década de 1990 é que algumas escolas de direito, sobretudo do Norte e Leste europeu, introduziram a clínica jurídica nos seus currículos. Mas foi já neste século que a experiência se alargou a universidades da Alemanha e dos países do Sul, com destaque para a Itália, em parte impulsionada pelo processo de Bolonha, mas também pelo reconhecimento da necessidade de reformar o ensino do direito. ${ }^{6}$ Alberto Alemanno e Lamin Khadar (2018), partindo desta necessidade, procuram responder se e de que modo a clínica jurídica pode transformar o ensino do direito nas universidades europeias. Contudo, a novidade do fenómeno e a falta de estudos empíricos que, com recurso a metodologias adequadas, evidenciem os impactos positivos que lhe são atribuídos tornam complexa e ainda prematura essa resposta.

Apesar de se tratar de um movimento global, com experiências em várias partes do mundo, é possível encontrar uma larga variedade de modelos de clínica jurídica refletindo, não só o contexto social e político da sociedade de referência, mas também os princípios orientadores dos currículos académicos onde se inserem. Neste âmbito saliento, pelo potencial de compromisso com os direitos humanos, a reflexão de Sousa Júnior et al. (2007) que deu a conhecer experiências de clínica jurídica no Brasil, evidenciando a importância da prática jurídica e judiciária na formação dos estudantes em vários domínios e situações da vida dos cidadãos (reclusão, violência doméstica contra menores, saúde, pensões alimentares, erro médico,

\footnotetext{
${ }^{6}$ Sobre a evolução das experiências de clínica jurídica na Europa, ver Clelia Bartoli (2016).
} 
direitos do consumidor, assédio moral no trabalho, deficiência, etc.). Aquelas experiências orientam-se por um duplo objetivo: construir uma prática jurídica comprometida com a procura sociojurídica por parte das classes populares e fomentar a consciência crítica dos estudantes para uma cultura de cidadania e de compromisso com os direitos humanos.

O enfoque do ensino nos direitos humanos não pode deixar, no entanto, de refletir a análise crítica de Santos à convivência "perturbadora" entre a "hegemonia global dos direitos humanos como linguagem de dignidade humana" e a realidade do silenciamento de sofrimento humano injusto que não é considerado uma violação dos direitos humanos, mostrando como a grande maioria da população mundial não é sujeito de direitos humanos, mas sim "objecto de discurso de direitos humanos" (Santos, 2013: 13). É isto que leva o autor a formular duas perguntas centrais: "Que outras linguagens de dignidade humana existem no mundo? E, se existem, são ou não compatíveis com a linguagem dos direitos humanos?" (ibidem). Ainda que os programas curriculares das faculdades incorporem a temática dos direitos humanos, o seu potencial transformador depende da capacidade de incluírem diferentes perspetivas críticas: a formação para os direitos humanos "não pode estar restrita ao estudo das normas que tratam dos direitos humanos, deve antes estabelecer uma relação dialógica com as lutas jurídicas e sociais pela cidadania e pelo reconhecimento de direitos" (Santos, 2014: 108-109).

$\mathrm{Na}$ reflexão crítica sobre o ensino do direito, a partir de dados empíricos, salienta-se, no contexto europeu, o estudo Menu for Justice Project, coordenado por Daniela Piana (Piana et al., 2013), cujo objetivo central foi o de recolher e analisar um conjunto de dados, qualitativos e quantitativos, que permitissem refletir comparativamente sobre o ensino do direito e a formação profissional dos atores judiciais em vários países europeus. ${ }^{7}$ No que respeita ao ensino do direito, o estudo analisa variáveis como a interação entre as faculdades de direito e os tribunais, a interdisciplinaridade, a presença do direito internacional e de temas de caráter internacional nos programas curriculares e as inovações no âmbito da metodologia de ensino. No que respeita à dimensão interação entre as faculdades de direito e os tribunais, os dados recolhidos permitem concluir, em algumas instituições de ensino e de investigação europeias, a existência de uma maior abertura à cooperação com as instituições do judiciário, seja diretamente com os tribunais, com outras organizações da justiça, ou com escritórios de

\footnotetext{
7 Alemanha, Áustria, Bélgica, Bulgária, Chipre, Dinamarca, Eslováquia, Eslovénia, Espanha, Estónia, França, Finlândia, Grécia, Holanda, Hungria, Irlanda, Islândia, Itália, Letónia, Lituânia, Luxemburgo, Malta, Noruega, Polónia, Portugal, Reino Unido, República Checa, Roménia e Suécia.
} 
advogados, embora se reconheça como residual a influência do judiciário na definição dos programas curriculares das faculdades de direito. Mas a existência dessa interação, mais ou menos sistemática entre os campos académico e judiciário, não pode ser validada, em si mesma, com potencial de transformação da cultura judiciária e de transformação do sistema judicial. Boaventura de Sousa Santos, na avaliação que faz sobre o ensino do direito no Brasil, chama a atenção para o facto de muitos dos professores serem selecionados apenas por critérios de prática profissional (advogados, juízes, promotores públicos) e para os riscos de um corpo docente constituído por especialistas de ensino antidialógico, contratados para "proferir alguns discursos semanais, que deverão ser repetidos fielmente em provas e trabalhos" (Santos, 2007: 74).

No campo das metodologias de ensino o projeto identifica três tipos de inovação: os estágios integrados na componente curricular, a clínica jurídica, o estudo de casos práticos, a utilização de ferramentas multimédias e os tribunais simulados (os moot courts). Embora tratando-se de experiências ainda incipientes, é reportada, em vários países, a existência em algumas das instituições de ensino do direito de, pelo menos, uma daquelas inovações, embora não seja clara a sua integração nos programas curriculares, os créditos atribuídos e os objetivos estratégicos que a elas presidem. Quanto à interdisciplinaridade, a conclusão vai no sentido de que os programas curriculares na maioria das faculdades de direito são compostos essencialmente por disciplinas jurídicas, embora haja cursos em que a presença das disciplinas não jurídicas tem algum peso relevante. A sua frequência é, em regra, facultativa, e nos cursos que combinam disciplinas jurídicas e não jurídicas, estas correspondem maioritariamente às designadas disciplinas não jurídicas tradicionais, como é o caso da economia ou da ciência política. As disciplinas não jurídicas inovadoras, como a sociologia, a contabilidade ou a gestão estão, em regra, arredadas dos programas curriculares, mantendo-se o tradicional fechamento das faculdades de direito ao conhecimento multidisciplinar e interdisciplinar.

Uma análise breve dos programas curriculares das faculdades de direito portuguesas, apresentados nas respetivas páginas eletrónicas, permite concluir que, em geral, também entre nós se verifica esse fechamento. Os programas curriculares evidenciam, por um lado, um débil investimento em áreas emergentes do saber jurídico e, por outro, uma formação técnico-burocrática sem especial ligação quer à prática jurídica, quer ao compromisso com os problemas sociais. A mudança ocorrida nalguns currículos e na articulação com a prática judiciária tem como objetivo central diversificar as possibilidades de especialização jurídica e as saídas profissionais, mas 
dentro do mesmo paradigma de ensino. Mantém-se ausente dos programas curriculares a reflexão teórica interdisciplinar que permitiria compreender o direito como um fenómeno social e político. Os programas curriculares das faculdades de direito portuguesas encaixam-se, por isso, na análise de Boaventura de Sousa Santos:

Em regra, o ensino jurídico até hoje praticado parte do pressuposto de que o conhecimento do sistema jurídico é suficiente para a obtenção de êxito no processo de ensino-aprendizagem. A necessária leitura cruzada entre o ordenamento jurídico e as práticas e problemas sociais é ignorada, encerrando-se o conhecimento jurídico e, consequentemente, o aluno, no mundo das leis e dos códigos. As pesquisas no direito estão ainda muito centradas na descrição de institutos, sem a devida contextualização social. (Santos, 2014: 108)

Para o autor, a mudança de paradigma exige que se ponha em causa o consenso hegemónico sobre o direito através de uma "nova atitude teórica, prática e epistemológica" (ibidem: 12), que denomina novo senso comum jurídico e que passa, designadamente, pela conceção de um direito plural, por contraponto ao dogmatismo jurídico e à teoria positivista do direito; pela necessidade de repolitizar o direito e a justiça como fatores de democratização, o que obriga à reconfiguração do papel dos tribunais; e pela ampliação da compreensão do direito como princípio e instrumento da transformação social politicamente legitimada (ibidem: 11-13).

Esta é, contudo, uma mudança que se evidencia muito difícil. No caso das universidades europeias, a forte tradição jus positivista torna difícil a renovação das faculdades de direito. A principal dificuldade decorre de fatores estruturais inerentes à universidade. Boaventura de Sousa Santos (1994, 2004 e 2017) tem produzido uma ampla reflexão sobre a crise da universidade, realçando o desinvestimento na universidade pública e a globalização mercantil da universidade como os dois fenómenos mais marcantes dessa crise. Não cabe aqui analisar essa reflexão. É, no entanto, importante ter-se presente que a reflexão sobre o ensino nas faculdades de direito está intimamente associada a uma reflexão mais vasta sobre o papel da universidade nas sociedades contemporâneas e sobre as condições que é necessário criar para que desempenhe esse papel.

\section{A formação dos magistrados deve estar no centro das políticas públicas da justiça}

A dificuldade em reformar as faculdades de direito acentua a importância da formação profissional dos atores judiciais, em especial dos magistrados. 
A questão central é a de saber se a formação, quer a formação inicial, quer a formação contínua, constitui atualmente um prolongamento das faculdades de direito ou, pelo contrário, está a ser orientada para responder à complexidade social e para contribuir ativamente no sentido de uma justiça mais democrática, mais eficiente e com mais qualidade. O estudo coordenado por Daniela Piana (Piana et al., 2013) acima referido, partindo da análise, quer dos programas de formação, quer de decisões judiciais, permite identificar um conjunto de caraterísticas inerentes à formação dos magistrados europeus que colocam os modelos formativos longe da capacidade de ultrapassar as deficiências do ensino do direito. Partindo dos problemas identificados nas várias experiências, considero que as questões que emergem como aquelas a que as políticas de formação dos Estados-membros devem dar especial atenção são as seguintes: a) ética e independência judicial (em alguns países, apesar das mudanças constitucionais, continuam a verificar-se sérias dificuldades na afirmação dos princípios da independência e da autonomia do judiciário); b) aplicação do direito, orientada por princípios gerais e por objetivos democraticamente definidos, e não apenas por regras jurídicas estritas, incentivando o poder judicial a responder, com responsabilidade democrática e cultura de cidadania, à diversidade e à complexidade das sociedades (como, por exemplo, ao multiculturalismo, à sociedade de austeridade e à precarização de direitos); c) resposta diferenciada e adequada à mediatização da justiça (o poder judicial e os magistrados têm que saber lidar, quer com o crescente interesse da comunicação social no campo do judiciário, quer com o escrutínio dos cidadãos); d) aquisição, por parte dos magistrados, de competências não jurídicas, que lhes permitam uma resposta judicial mais eficiente e com mais qualidade (quer através da melhor compreensão dos fenómenos sociais que estão no lastro dos processos, quer procurando trabalhar uma resposta alargada com outras organizações do Estado ou da sociedade); e) formação orientada para a mudança de cultura judicial e para a gestão processual, que permita responder, com qualidade e eficiência, à complexidade social, às especificidades e à urgência dos casos (os tribunais estão organizados para tratarem todos os casos da mesma forma burocrática e rotineira); f) formação orientada para a simplificação da linguagem e da mensagem (a comunicação dos tribunais e dos magistrados, seja através dos despachos e decisões, seja na comunicação oral, é excessivamente cifrada, requerendo quase sempre intermediação).

Em Portugal, com a publicação do Decreto-Lei n. ${ }^{\circ}$ 374-A/79, de 10 de setembro, que criou o Centro de Estudos Judiciários (CEJ), efetivou-se a rutura com o modelo de recrutamento direto para o exercício da função de magistrado e de formação em exercício. A opção foi a da institucionalização 
e profissionalização da formação dos magistrados "através da constituição de um corpo de formadores especializados e da criação de um estabelecimento adequado e com competência própria" (Lúcio, 1986: 299). A criação de uma escola, com a estrutura do CEJ, constitui um avanço significativo na preparação das magistraturas. Da suficiência do conhecimento teórico e do "aprender fazendo" passou-se para políticas formalmente enquadradas em que a formação prévia à entrada na profissão assume significativa relevância. Estrategicamente, o CEJ pretendia afirmar-se como uma estrutura que assegurava a construção das magistraturas, judicial e do Ministério Público, atendendo a duas principais preocupações: garantir a adequada independência do poder judicial face ao poder político e entre os próprios profissionais; e construir um corpo profissional capaz de acompanhar e responder às transformações, quer da sociedade, quer do sistema judicial de forma culturalmente esclarecida, com elevados padrões de qualidade técnico-jurídica. A questão que se coloca é a de saber se o modelo de formação então implementado, e que as alterações legais posteriores não colocaram em causa, tem ou não potencial para responder às transformações sociais, aos desafios que a sociedade coloca aos tribunais e à renovação democrática da cultura judiciária.

O modelo de escola, quer entre nós, quer nas várias experiências europeias, é tendencialmente aceite como o modelo de formação de magistrados mais adequado no sentido de garantir a edificação de um corpo profissional independente, crítico e inovador, por contraposição a um modelo reprodutivo. Mas, se há consenso quanto ao modelo, os conteúdos programáticos, o perfil do corpo docente e as metodologias de formação são dimensões que emergem no debate sobre a reforma da formação de magistrados. Considerando estas dimensões, a evolução da formação mantém-se, no essencial, fiel ao modelo técnico-burocrático: prevalência das matérias jurídicas, estruturadas à semelhança das faculdades de direito em torno dos núcleos tradicionais do direito, e o mesmo perfil do corpo docente, constituído por magistrados. A ausência de uma formação multidisciplinar e muito menos interdisciplinar contribui para o tratamento parcelar dos fenómenos sociais, compartimentados nas várias disciplinas jurídicas. O alargamento disciplinar, nos últimos anos, não foi muito além de algum investimento em outras áreas do direito, como o direito europeu e o direito constitucional, no inglês jurídico e nas tecnologias de informação e comunicação, mas com carga horária muito mais reduzida, comparativamente com as áreas tradicionalmente assumidas como nucleares, nas quais se destacam o direito civil e penal. Alguma multidisciplinaridade é tratada muito lateralmente em ambiente de conferência. Aliás, o perfil do seu corpo docente não 
permitiria outra abordagem. Sem grandes espaços de reflexão multidisciplinar na aprendizagem quotidiana dos futuros magistrados, a tendência é para a reprodução, estreitando-se a margem de proatividade e de inovação na interpretação dos factos, na aplicação do direito e na mudança da cultura judiciária. Perdura, por isso, nas suas caraterísticas essenciais, o retrato-robô dos magistrados em Portugal, traçado por Santos (2000, 2007 e 2014). Nesse retrato domina uma cultura normativista, técnico-burocrática, assente em três grandes ideias: a autonomia do direito, isto é, a ideia de que o direito é um fenómeno totalmente diferente de outros fenómenos sociais e autónomo em relação à sociedade; uma conceção restritiva do que é esse direito ou do que são os autos aos quais o direito se aplica; e uma conceção burocrática ou administrativa dos processos. Esta cultura normativista, técnico-burocrática, manifesta-se de múltiplas formas: prioridade do direito civil e penal; cultura generalista; desresponsabilização sistémica; refúgio burocrático; isolamento social; e independência como autossuficiência (Santos, 2000, 2007 e 2014). Permanece, assim, por cumprir a recomendação geral do estudo do Observatório Permanente da Justiça do Centro de Estudos Sociais "O sistema judicial e os desafios da complexidade social - Novos caminhos para o recrutamento e a formação de magistrados”, de que:

a formação tem de criar condições para se formarem magistrados dotados de um sólido apetrechamento técnico-jurídico, aptos para o exercício das funções segundo critérios éticos e deontológicos, de independência, de responsabilidade, com elevado conhecimento crítico sobre o papel e as funções dos tribunais na sociedade, bem como sobre o contexto social do seu desempenho funcional e sobre os desafios do futuro. (Santos e Gomes, 2011: 508-509) ${ }^{8}$

\section{Duas palavras-chave devem orientar a formação contínua: alargamento e renovação}

A formação contínua é hoje entendida como indispensável à capacitação dos magistrados para o exercício da profissão e é reivindicada pelos próprios magistrados, quer individualmente, quer através das suas organizações de classe. No quadro europeu destaca-se o apoio que a União Europeia tem dado à formação contínua dos atores judiciais através de diferentes programas de apoio financeiro à formação nos Estados-membros, no âmbito do quadro financeiro plurianual 2014-2020, bem como a promoção de

\footnotetext{
${ }_{8}^{8}$ Partindo deste objetivo estratégico, o estudo apresenta um conjunto de linhas orientadoras e de propostas concretas de reforma do modelo de recrutamento e de formação de magistrados (Santos e Gomes, 2011: 491-534).
} 
instituições, como a Rede Europeia de Formação Judiciária, e a relevância assumida na maioria dos países, ainda que com soluções organizacionais diferenciadas, no domínio das políticas públicas. ${ }^{9} \mathrm{Na}$ experiência comparada identificam-se diferentes soluções, quer quanto à obrigatoriedade de frequência de formação após a nomeação definitiva como magistrado, quer quanto à competência relativamente à sua organização (Ministério da Justiça, Conselhos Superiores ou outro organismo independente daqueles dois). Independentemente do modelo, há uma crescente atenção, na maioria dos países, voltada para a formação contínua dos magistrados através do desenvolvimento de programas de formação, seja com o objetivo de capacitação geral, seja especializada (Hammergren, 1998; Oberto, 2003; Stawa, 2005; Thomas, 2006; Dallara e Amato, 2013). A formação dos atores judiciais no decurso do exercício profissional é considerada fundamental para a atualização e aprendizagem de novos conhecimentos técnico-jurídicos para uma melhor compreensão dos fenómenos sociais, como instrumento de aplicação eficaz de reformas legais, como via de especialização e enquanto fórum de discussão de problemas e de boas práticas.

Também em Portugal, o tema da formação contínua tem vindo a ganhar centralidade no debate sobre a justiça e relevância institucional. A formação contínua dos magistrados, judiciais e do Ministério Público, tal como a formação inicial, é da competência do CEJ que deve elaborar, em articulação com os Conselhos Superiores da Magistratura, dos Tribunais Administrativos e Fiscais e do Ministério Público, um plano anual de formação. No plano legal, além do direito à formação, que passou a ser consagrado nos Estatutos dos Magistrados Judiciais e do Ministério Público, a lei passou a prever que a frequência e o aproveitamento em ações de formação contínua sejam elementos a considerar para a progressão na carreira, bem como para a colocação em tribunais de competência especializada ou para o exercício de determinados cargos do Ministério Público. ${ }^{10}$ Contudo, as alterações no

\footnotetext{
9 O relatório da Comissão Europeia "European Judicial Training 2017” (Comissão Europeia, 2017) traça um retrato da formação judicial implementada em 2016, de acordo com um inquérito aplicado às autoridades dos Estados-membros, às redes europeias de profissionais do direito e às principais instituições que realizam formação destinada aos atores judicias a nível europeu. Esse retrato identifica discrepâncias assinaláveis entre os diferentes atores judiciais e entre os Estados-membros e dimensões que carecem, ainda, de melhorias, como o investimento em formação para outros atores judiciais para além dos juízes, bem como o desenvolvimento de programas de formação continuada, considerando que $66 \%$ das ações de formação realizadas naquele ano teve uma duração inferior a dois dias. Também o relatório do Parlamento Europeu "The Training of Judges and Legal Practitioners" (Parlamento Europeu, 2017) identifica algumas dificuldades na formação dos atores judiciais a que a política de formação deve dar resposta. ${ }^{10} \mathrm{Cf}$. a Lei . $^{\circ} 2 / 2008$, de 14/01, que regula o ingresso nas magistraturas, a formação de magistrados e a natureza, estrutura e funcionamento do CEJ, alterada pela Lei n. ${ }^{\circ} 60 / 2011$, de 28/11 e posteriormente pela Lei n. ${ }^{\circ}$ 45/2013, de 03/07.
} 
plano da lei não significaram profundas mudanças na prática. Desde logo, a formação especializada não é requisito para a colocação em tribunais de competência especializada. Entre nós, a especialização dos tribunais continua a traduzir-se apenas em tribunais ou organizações do Ministério Público onde entram e são tramitados determinado tipo de processos, mas a colocação, quer dos magistrados, quer dos funcionários não é precedida de qualquer formação especializada na área. Por outro lado, a valorização da formação para a progressão da carreira, num quadro de escassez de oferta formativa - há uma seleção pelos respetivos conselhos dos magistrados que declarem pretender frequentar ações de formação -, pode ter um duplo efeito perverso: instrumentalização da procura de formação, podendo significar a frequência de ações de formação sem impacto direto no exercício de funções desempenhadas e restrição do acesso à formação de magistrados mais jovens, ainda longe da possibilidade de promoção. No plano disciplinar, a formação contínua mantém-se ainda muito ancorada em saberes técnico-jurídicos, com o objetivo principal de atualização dos quadros normativos no âmbito de temas mais recorrentes no trabalho das magistraturas.

Apesar de alguma evolução positiva neste plano, em vários estudos levados a cabo no âmbito do Observatório Permanente da Justiça Portuguesa (OPJ) são denunciadas fragilidades dos programas formativos, quer considerando o baixo número de ações de formação, quer as matérias sobre que versam, com impacto negativo na eficiência e na qualidade da administração da justiça. ${ }^{11}$ As carências formativas mais evidenciadas são as seguintes: a interpretação juridicamente inovadora, de acordo com uma perspetiva emancipatória dos direitos humanos, da realidade social que subjaz aos autos; a aplicação das reformas; a especialização em determinadas áreas, como, por exemplo, no âmbito da criminalidade económica complexa e de outros tipos de criminalidade grave (racismo, violência doméstica, violência contra as crianças), da justiça de família e de crianças, da justiça laboral; a gestão processual, incluindo novos métodos de trabalho; e a utilização eficiente das novas tecnologias de comunicação e de informação. Saliento a importância da criação de programas de formação, com recurso a metodologias adequadas, designadamente através de ateliers de análise crítica de jurisprudência, e com um corpo docente multidisciplinar, que permitam inovar na resposta judicial a situações de maior urgência

\footnotetext{
${ }^{11}$ Destaca-se, a este propósito, os seguintes estudos do OPJ: "A sociedade civil organizada e os tribunais: a mobilização do direito e da justiça em Lisboa, Luanda, Maputo e São Paulo” (2014); "Estudo avaliativo das decisões judiciais em matéria de violência doméstica" (2014); "O sistema judicial e os desafios da complexidade social: novos caminhos para o recrutamento e formação de magistrados" (2011); “A indemnização da vida e do corpo na lei e nas decisões judiciais” (2010).
} 
e vulnerabilidade social, como é, por exemplo, o caso da violência doméstica, dos acidentes de trabalho, de casos que envolvem populações imigrantes de estratos sociais mais carenciados em que as dificuldades linguísticas e as diferenças culturais ampliam a distância cultural, comunicacional e simbólica, gerando novas formas de vulnerabilidade de fragilidade social. ${ }^{12}$ Facilmente se entende que uma formação preocupada com a compreensão dos fenómenos sociais que estão no lastro dos processos judiciais e solidamente sustentada na valorização dos direitos humanos determinará, por parte dos magistrados, diferentes valorizações das condutas, dos factos e do direito que se lhes aplica. O contributo do sistema de justiça para a promoção da cidadania, para a correção das desigualdades e para a coesão social depende muito dessa capacitação dos atores judiciais, em especial dos magistrados judiciais.

\section{Conclusão}

A política de formação dos atores judiciais enquanto tema autónomo só muito esporadicamente tem visibilidade no discurso mediático sobre a justiça e, quando ocorre, tende a ser instrumental ao tema central do eixo discursivo. Este é, contudo, um tema refletido em vários estudos de avaliação do desempenho funcional do sistema judicial e é argumento recorrente nos discursos sobre a justiça, por parte de atores internos e externos ao sistema, designadamente em áreas como a violência doméstica, a criminalidade grave e complexa ou a justiça de crianças. Há um traço comum a todas essas análises: a importância de reformar a política de formação dos atores judiciais como condição de eficiência dos tribunais e de qualidade da justiça.

Partindo das análises sobre o sistema de justiça desenvolvidas no âmbito do Centro de Estudos Sociais, saliento como principal conclusão o descompasso entre as profundas transformações da sociedade portuguesa ocorridas nas últimas décadas e os desafios que essas transformações colocam ao sistema judicial, por um lado, e, por outro, a orientação tecnocrática dos modelos de ensino do direito e de formação, caraterizada pelo fechamento do direito à sociedade, à interdisciplinaridade e às inovações com potencial de criação de uma cultura judiciária capaz de responder, com qualidade e eficiência, tanto às expetativas dos negócios, dos conflitos de cidadãos e de empresas, ao combate à criminalidade grave e complexa, como também às vulnerabilidades e urgências sociais. Os programas de formação, quer das faculdades de direito, quer no âmbito da formação profissional têm

${ }_{12}$ Conferir os estudos do OPJ: "Estudo avaliativo das decisões judiciais em matéria de violência doméstica" (2014) e "A indemnização da vida e do corpo na lei e nas decisões judiciais" (2010). 
de incorporar a noção de direito enquanto fenómeno social, bem como a essencialidade de conhecer a sociedade, não como um apêndice, mas exatamente como constitutiva do direito.

Revisto por Rita Cabral

\section{Referências bibliográficas}

Alemanno, Alberto; Khadar, Lamin (2018), Reinventing Legal Education: How Clinical Education Is Reforming the Teaching and Practice of Law in Europe. Cambridge: Cambridge University Press.

Bartoli, Clelia (2016), Legal Clinics in Europe: For a Commitment of Higher Education in Social Justice. Palermo: Diritto \& Questioni Pubbliche.

Berkmanas, Tomas (2013), "Innovative and Interdisciplinary Contents and Programmes in Graduate Legal Studies: Lessons Learned”, in Daniela Piana; Philip Langbroek; Tomas Berkmanas; Ole Hammerslev; Otilia Pacurari (orgs.), Legal Education and Judicial Training in Europe - The Menu for Justice Project Report. Den Haag: Eleven International Publishing, 93-108.

Bodiguel, Jean-Luc (1991), Les magistrats, un corps sans âme? Paris: Presses Universitaires de France.

Comissão Europeia (2017), European Judicial Training 2017. Bruxelles: Comissão Europeia. Dallara, Cristina; Amato, Rosanna (2013), "Building Blocks for Legal and Judicial Training”, in Daniela Piana; Philip Langbroek; Tomas Berkmanas; Ole Hammerslev; Otilia Pacurari (orgs.), Legal Education and Judicial Training in Europe - The Menu for Justice Project Report. Den Haag: Eleven International Publishing, 255-280.

Di Federico, Giuseppe (coord.) (1989), Caratteristiche socio-culturali della magistratura - Le tendenze degli ultimo venti anni. Padova: CEDAM-Casa Editrice Dott. Antonio Milani.

Di Frederico, Guiseppe (coord.) (2005), Recruitment, Professional Evaluation and Career of Judges and Public Prosecutors in Europe: Austria, France, Germany, Italy, The Netherlands and Spain. Bologna: Istituto di Ricerca sui Sistemi Giudiziari - Consiglio Nazionale delle Richerche.

Épineuse, Harold (2008), Évaluation de la formation des magistrats en France et en Europe - Bilan et perspectives. Paris: L'Institut des Hautes Études sur la Justice.

Ferreira, António Casimiro; Dias, João Paulo; Gomes, Conceição; Duarte, Madalena; Fernando, Paula; Campos, Alfredo (2013), Contextos e desafios da transformação das magistraturas: o contributo dos estudos sociojurídicos. Porto: Vida Económica.

Ferreira, António Casimiro (coord.) (2014), "Quem são os nossos magistrados? Caracterização profissional dos juízes e magistrados do Ministério Público em Portugal”. Relatório final do projeto. Coimbra: Centro de Estudos Sociais. 
Gane, Christopher; Huang, Robin Hui (2016), Legal Education in the Global Context: Opportunities and Challenges. London: Routledge.

Garapon, Antoine (1998), O guardador de promessas: justiça e democracia. Lisboa: Instituto Piaget.

Gent, Ernst van Bemmelen van (2012), “Legal Education: A New Paradigm”, Bynkershoek Law Review, 2-18.

Gomes, Conceição; Fernando, Paula; Ribeiro, Tiago; Oliveira, Ana; Duarte, Madalena (2016), Violência doméstica: estudo avaliativo das decisões judiciais. Lisboa: Comissão para a Cidadania e a Igualdade de Género.

Hammergren, Linn (1998), Judicial Training and Justice Reform. Washington, D.C.: USAID - United States Agency for International Development. Consultado a 15.03.2018, em http://pdf.usaid.gov/pdf_docs/pnacd021.pdf.

Lúcio, Álvaro Laborinho (1986), “O magistrado hoje - Actuação e formação”, Revista Crítica de Ciências Sociais, 18/19/20, 291-309.

Mandel, Michael (1995), "Legal Politics Italian Style”, in C. Neal Tate; Torbjörn Vallinder (orgs.), The Global Expansion of Judicial Power. New York: University Press, 243-261.

Makowicz, Bartosz (2013), "Compliance: Challenge or Chance for Legal Education?”, in Pasquale Policastro (orgs.), Towards Innovation in Legal Education. Den Haag: Eleven International Publishing, 23-28.

Micklitz, Hanz-Wolfgang (2016), “The Bifurcation of Legal Education - National vs Transnational”, in Christopher Gane; Robin Hui Huang (orgs.), Legal Education in the Global Context: Opportunities and Challenges. London: Routledge, 43-60.

Nelken, David (2004), "Using the Concept of Legal Culture”, Australian Journal of Legal Philosopby, 29, 1-28.

Oberto, Giacomo (2003), Recrutement et formation des magistrats en Europe - Etude Comparative. Strasbourg: Edition du Conseil de l'Europe.

Parlamento Europeu (2017), The Training of Judges and Legal Practitioners. Bruxelles: Parlamento Europeu.

Pérez Lledó, Juan Antonio (2002), “Teoría y práctica en la enseñanza del Derecho”, AFDUAM - Anuario de la Facultad de Derecho de la Universidad Autónoma de Madrid, 6, 197-268.

Pérez Lledó, Juan Antonio (2007), “Teoría y práctica en la enseñanza del Derecho”, Revista sobre enseñanza del Derecho, 5(9), 85-189.

Piana, Daniela; Langbroek, Philip; Berkmanas, Tomas; Hammerslev, Ole; Pacurari, Otilia (orgs.) (2013), Legal Education and Judicial Training in Europe - The Menu for Justice Project Report. Den Haag: Eleven International Publishing.

Quinn, Mae C. (2009), “The Modern Problem-Solving Court Movement: Domination of Discourse and Untold Stories of Criminal Justice Reform”, Washington University Journal of Law \& Policy, 31, 57-82. 
Ramoneda, Josep (2018), "Buscar una salida - Un problema político se ha convertido en judicial y a Rajoy se le escapa de las manos. El que marca los tiempos políticos es el juez Llarena”, jornal El País, de 24 de março. Consultado a 24.03.2018, em https:// elpais.com/ccaa/2018/03/23/catalunya/1521820496_578827.html.

Reich, Norbert (2002) "Recent Trends in European Legal Education: The Place of the European Law Faculties Association”, Penn State International Law Review, 21(1), Article 5, 21-38.

Santos, Boaventura de Sousa (1994), Pela mão de Alice: o social e o político na pós-modernidade. Porto: Edições Afrontamento.

Santos, Boaventura de Sousa (2000), "Que formação para os magistrados nos dias de hoje?”, Que formação para os magistrados nos dias de boje? Lisboa: Sindicato dos Magistrados do Ministério Público, 25-44.

Santos, Boaventura de Sousa (2002), "Direito e democracia. A reforma global da justiça", in José Manuel Pureza; António Casimiro Ferreira (orgs.), A teia global: movimentos sociais e instituições. Porto: Edições Afrontamento, 125-176.

Santos, Boaventura de Sousa (2004), A Universidade no séc. XXI: para uma reforma democrática e emancipatória da Universidade. São Paulo: Cortez Editora [3. ${ }^{\mathrm{a}}$ ed.].

Santos, Boaventura de Sousa (2007), Para uma revolução democrática da justiça. São Paulo: Cortez Editora.

Santos, Boaventura de Sousa (2013), Se Deus fosse um activista dos direitos humanos. Coimbra: Edições Almedina.

Santos, Boaventura de Sousa (2014), Para uma revolução democrática da justiça. Coimbra: Edições Almedina.

Santos, Boaventura de Sousa (2017), Decolonising the University. The Challenge of Deep Cognitive Justice. Cambridge: Cambridge Scholars Publishing.

Santos, Boaventura de Sousa; Marques, Maria Manuel Leitão; Pedroso, João; Ferreira, Pedro Lopes (1996), Os tribunais nas sociedades contemporâneas: o caso português. Porto: Edições Afrontamento.

Santos, Boaventura de Sousa (dir. científico); Gomes, Conceição (coord.); Pedroso, João (coord.) (2001), "O recrutamento e formação de magistrados: uma proposta de renovação. Análise comparada de sistemas e do discurso judiciário em Portugal”. Relatório final do projeto. Coimbra: Centro de Estudos Sociais/Observatório Permanente da Justiça.

Santos, Boaventura de Sousa; Pedroso, João; Branco, Patrícia (2006), "O recrutamento e a formação de magistrados: análise comparada de sistemas em países da União Europeia”. Relatório final do projeto. Coimbra: Centro de Estudos Sociais/ Observatório Permanente da Justiça.

Santos, Boaventura de Sousa (dir.); Gomes, Conceição (coord.) (2011), “O sistema judicial e os desafios da complexidade social - Novos caminhos para o recrutamento 
e a formação de magistrados”. Relatório final do projeto. Coimbra: Centro de Estudos Sociais/Observatório Permanente da Justiça.

Sousa Júnior, José Geraldo; Costa, Alexandre Bernardino; Maia Filho, Mamede Said (2007), A prática jurídica na UnB, Coleção Prática Jurídica, vol. 1. Brasília: Universidade de Brasília/Faculdade de Direito.

Stawa, Mag. Georg (2005), "Recruitment, Professional Evaluation and Career of Judges and Public Prosecutors in Austria", in Giuseppe Di Frederico (coord.), Recruitment, Professional Evaluation and Carrer of Judges and Public Prosecutors in Europe: Austria, France, Germany, Italy, The Netherlands and Spain. Bologna: Istituto di Ricerca sui Sistemi Giudiziari - Consiglio Nazionale delle Ricerche, 1-42.

Tate, Neal; Vallinder, Torbjörn (orgs.) (1995), The Global Expansion of Judicial Power. New York/London: New York University Press.

Thomas, Cheryl (2006), Review of Judicial Training and Education in Other Jurisdictions. Consultado a 15.03.2018, em http://www.retawprojects.com/uploads/judicial_training.pdf.

Toharia, José Juan (1975), El juez español - Un análisis sociológico. Madrid: Editorial Tecnos.

Toharia, José Juan (1989), “El juez español: quince años después”, Revista del Centro de Estudios Constitucionales, 3, 345-364.

Vázquez, Rodolfo (2008) “Concepciones filosóficas y enseñanza del Derecho”, Academia. Revista sobre enseñanza del Derecho, 6(12), 221-237.

Wolf, Robert V. (2007), Principles of Problem-Solving Justice. New York: Center for Court Innovation.

\section{Conceição Gomes}

Centro de Estudos Sociais da Universidade de Coimbra | Observatório Permanente da Justiça

Portuguesa (OPJ) | Unidade de Formação Jurídica e Judiciária (UNIFOJ)

Colégio de S. Jerónimo, Largo D. Dinis, Apartado 3087, 3000-995 Coimbra, Portugal

Contacto: cgomes@ces.uc.pt

\section{The Role of Judicial Training to the Justice Transformation}

Judicial training should be guided by the strategic objective of developing a judicial culture committed as much to the quality, efficiency and transparency of justice as to the democratic activism of the courts,

\section{La formation de magistrats comme instrument de transformation de la justice}

La formation d'acteurs judiciaires doit être guidée par l'objectif stratégique de la création d'une culture juridique fortement engagée, tant en matière de qualité, 
be it in the promotion of human rights and fundamental rights or in combating serious crime, namely corruption. The key question is whether training models, either in law schools or via professional training, offer the potential to achieve this strategic purpose. As the preponderance of judicial training reflects a formalist and technocratic character, and discounts the relevance of inter-disciplinarity and innovations capable of improving this judicial culture, training policy should assume a central position within the strategic agenda dedicated to justice reform.

Keywords: courts; justice reform; legal culture; magistrates; professional training. d'efficience et de transparence de la justice, que par son activisme démocratique, qu'il s'agisse de la promotion des droits humains et des droits fondamentaux ou du combat contre la criminalité grave, en particulier contre la corruption. La question centrale qui se pose est celle de savoir si les modèles de formation, que ce soit des facultés de droit ou de la formation professionnelle, sont en mesure de répondre à cet objectif stratégique. Le choix de la primauté d'une formation à l'orientation technocratique, formaliste et fermée à l'interdisciplinarité et aux innovations comme potentiel de création de cette culture judicaire requiert que la politique de formation soit placée au centre des agendas stratégiques de la réforme de la justice.

Mots-clés: culture juridique; formation professionnelle; magistrats; réforme de la justice; tribunaux. 
